\title{
Stage II Laryngeal Cancer AJCC v8
}

National Cancer Institute

\section{Source}

National Cancer Institute. Stage II Laryngeal Cancer A/CC v8. NCI Thesaurus. Code C133159.

Stage II includes: T2, N0, M0. T2: Supraglottis: Tumor invades the mucosa of more than one adjacent subsite of suprag lottis or glottis or region outside the supraglottis (e.g., mucosa of base of the tongue, vallecula, medial wall of pyriform sinus) without fixation of the larynx. Glottis: Tumor extends to supraglottis and/or subg lottis, and/or with impaired vocal cord mobility. Subg lottis: Tumor extends to vocal cord(s) with normal or impaired mobility. N0: No regional lymph node metastasis. M0: No distant metastasis. (AJCC 8th ed.) 